\title{
Awareness About Hyperbaric Prilocaine Among Dental Students
}

\author{
Prashaanthi.N ${ }^{1}$, Dhanraj Ganapathy ${ }^{2}$ and Revathi Duraisamy ${ }^{3}$ \\ ${ }^{1}$ Saveetha Dental College and Hospitals, Saveetha Institute of Medical \\ and Technical Sciences(SIMATS), Saveetha University, Chennai, India \\ ${ }^{2}$ Saveetha Dental College and Hospitals, Saveetha Institute of Medical \\ and Technical Sciences(SIMATS), Saveetha University, Chennai, India \\ ${ }^{3}$ Senior Lecturer, Department of Prosthodontics, Saveetha Dental College and Hospitals, Saveetha \\ Institute of Medical and Technical Sciences(SIMATS), Saveetha University, Chennai, India
}

\section{ABSTRACT}

Hyperbaric formulation of local anesthetic solutions have some advantages over plain solutions. The hyperbaric solutions are used in various fields of medicine due to their properties. The aim of this study was to assess the awareness about hyperbaric prilocaine among dental students.This study included 150 dental students in a dental hospital during the month of December 2019. Pre tested questionnaire was distributed among the students through an online link. Data was tabulated and results were obtained.Descriptive and chi square statistics were performed.Out of 150 patients, 6 students (44\%) were under 18-20 years and 84 students (56\%) were under 21-25 years age groups. Out of 150 students ,87 students (58\%) were males and 63 students $(42 \%)$ were females. On analysing the awareness of hyperbaric prilocaine among students, $88 \%$ had known about hyperbaric oxygen and 12\% were not aware about hyperbaric prilocaine. There was a significant association between age groups and awareness among dental students $(p<0.05)$ while no statistically significant was found between gender and awareness among dental students ( $p>0.05)$. Within the limitations of the present study, the awareness about the uses and properties of hyperbaric prilocaine was moderate.

KEY WORDS: HYPERBARIC PRILOCAINE;RAPID;AWARENESS;LIDOCAINE;DENTAL STUDENTS.

\section{INTRODUCTION}

Prilocaine is a local anesthetic agent characterized by intermediary potency and duration and rapid onset of action. As a hyperbaric formulation of 5\% solution, it was introduced and has been successfully used for spinal anesthesia since 1960.(Manassero and Fanelli, 2017)A

\section{ARTICLE INFORMATION}

*Corresponding Author: dhanraj@saveetha.com

Received 15th June 2020 Accepted after revision 10th August 2020

Print ISSN: 0974-6455 Online ISSN: 2321-4007 CODEN: BBRCBA

Thomson Reuters ISI Web of Science Clarivate Analytics USA and Crossref Indexed Journal

\section{Clarivate
Analytics}

NAAS Journal Score 2020 (4.31) SJIF: 2020 (7.728)

A Society of Science and Nature Publication,

Bhopal India 2020. All rights reserved.

Online Contents Available at: http//www.bbrc.in/

Doi: http://dx.doi.org/10.21786/bbrc/13.7/33 new formulation of $2 \%$ plain and hyperbaric solution is currently available in Europe. Because of its decreased incidence of transient neurological symptoms, prilocaine is suggested as a substitute to lidocaine and mepivacaine in spinal anesthesia for ambulatory surgery, as well as a potential alternative to low doses of long-acting local anesthetics. (Kreutziger et al., 2010)

Prilocaine with its 2\% hyperbaric formulation (HP), developed in recent times, showed fast onset of action and rapid regression of motor block compared to other local anesthetics without noteworthy side-effects when used intrathecally.(Ambrosoli et al., 2016) Literature suggests a dose ranging between 40 and $60 \mathrm{mg}$ of prilocaine for lower extremities and lower abdominal procedures lasting up to $90 \mathrm{~min}$, whereas a dose ranges 
from 10 to $30 \mathrm{mg}$ is appropriate for perineal surgical procedures. Readiness for discharge occurs in $4 \mathrm{~h}$ from spinal administration.(Lacroix et al., 2019)With the use of large doses of long-acting local anesthetics, delay of discharge emerged as a growing problem, although small doses demonstrated a wide variability in block duration and failure rate.Due to its intermediate duration of action and the lower incidence of TNS, prilocaine has been proposed as a valuable alternative to lidocaine as well as to small doses of long-acting local anesthetics for short procedures performed under spinal anesthesia. (St George et al., 2018)

Since prilocaine has the disadvantage of methemoglobinemia, hyperbaric prilocaine has been introduced and is in use with various fields of medicine. They are constantly used in spinal anesthesia for their rapid onset and offset actions and their short acting nature. They have been used in perianal surgeries, arthroplasty knee surgeries and various other surgeries due to their less toxic effect and also their rapid onset of action and regression of the motor block (Kaban et al., 2014; St George et al., 2018; Palumbo et al., 2019). There are more advantages of using hyperbaric prilocaine as a local anesthetic agent in the field of dentistry too but there are no studies highlighting the use of hyperbaric prilocaine in dentistry.

Previously our department has published extensive research on various aspects of prosthetic dentistry ('Evaluation of Corrosive Behavior of Four Nickelchromium Alloys in Artificial Saliva by Cyclic Polarization Test:An in vitro Study', 2017; Ganapathy, Kannan and Venugopalan, 2017; Jain, 2017a, 2017b; Ranganathan, Ganapathy and Jain, 2017; Ariga et al., 2018; Gupta, Ariga and Deogade, 2018; Anbu et al., 2019; Ashok and Ganapathy, 2019; Duraisamy et al., 2019; Varghese, Ramesh and Veeraiyan, 2019), this vast research experience has inspired us to research about the awareness on hyperbaric prilocaine among dental students.

\section{MATERIAL AND METHODS}

The study was done in an online setting among the dental students in the month of December 2019 in a private dental college in Chennai. Institutional review board approval was obtained for this survey based analysis. 2 reviewers [Primary investigator \&t guide] were involved in this study.

The sample size of 150 participants of age group 18-25 years including dental students from first year to interns both males and females were selected by a simple random sampling method studying in a private dental college. The students who were not willing to take part in the survey were excluded from the study. Randomisation [for all variables] was followed to minimise the bias. Pre tested questionnaires where the internal validity was the homogenisation and replication of experiment. Cross verification with existing studies was the external validity of this study.
The set of questionnaires which includes gender, questions on awareness were circulated among the participants through an online link. The results were collected and tabulated. Then the results were exported for statistical analysis to SPSS statistical software. Both descriptive ( frequency of the responses) and inferential statistics (Chi - square tests) were done and the results were presented in the forms of graphs.

\section{RESULTS AND DISCUSSION}

In the present study, out of 150 patients, 66 students (44\%) were under 18-20 years and 84 students (56\%) were under 21-25 years age groups. [FIgure 1] Out of 150 students ,87 students (58\%) were males and 63 students (42\%) were females. [FIgure 2]

Figure 1: Pie chart showing the age distribution among dental students. The higher participation was seen among 21-25 years age groups (green).

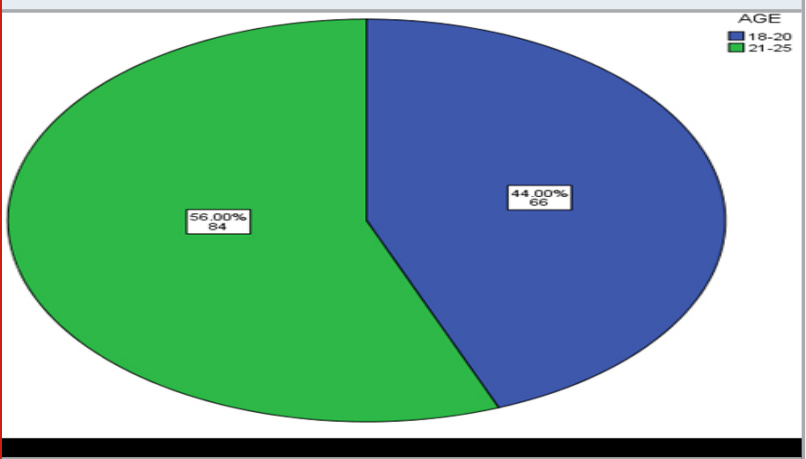

Figure 2: Pie chart showing the gender distribution among dental students. Males (58\%) (blue) have participated more than females (42\%) (green).

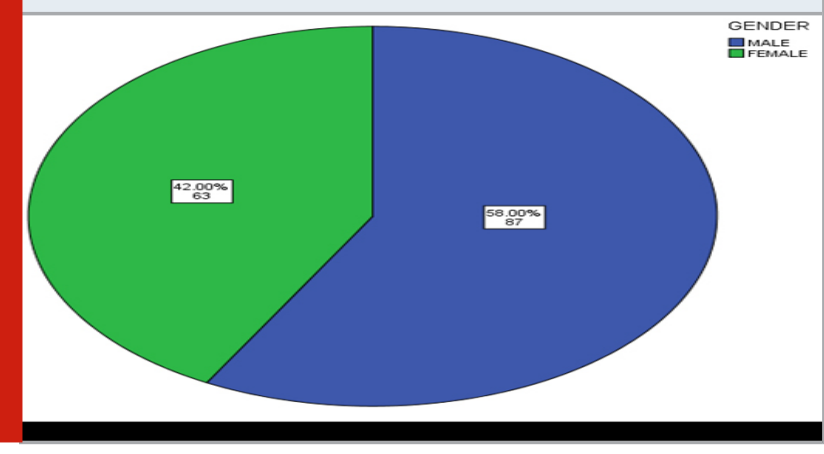

Figure 3: Pie chart showing the percentage of students awareness about hyperbaric prilocaine. 88\%(blue) were aware about hyperbaric prilocaine.

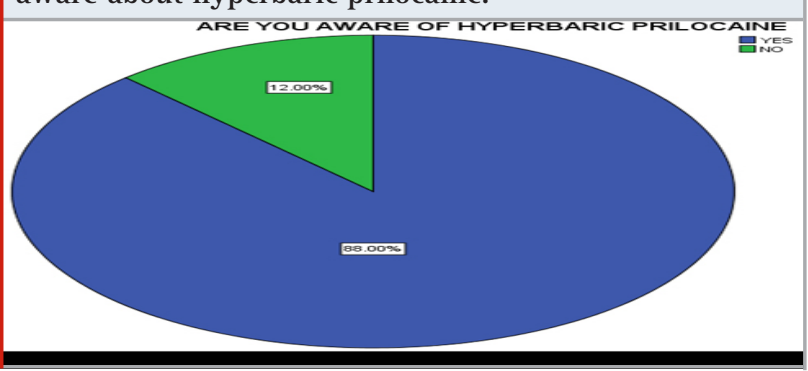


On analysing the awareness of hyperbaric prilocaine among students, 88\% had known about hyperbaric oxygen and 12\% were not aware about hyperbaric prilocaine. [FIgure 3] On assessing the awareness of the type of prilocaine, $99.3 \%$ of students have correctly answered as amide and $8.67 \%$ of students have answered as ester. [FIgure 4]

Figure 4: Pie chart showing the percentage of dental students awareness about the type of anesthetic agent. $91.3 \%$ (blue) were aware that prilocaine is a type of amide.

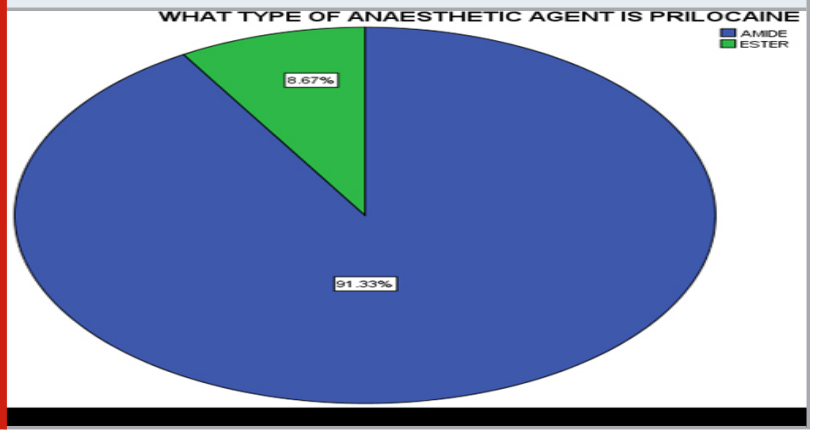

Figure 5: Pie chart showing the percentage of dental students awareness about hyperbaricity and onset of action. $68.67 \%$ (blue) were aware about the hyperbaricity.

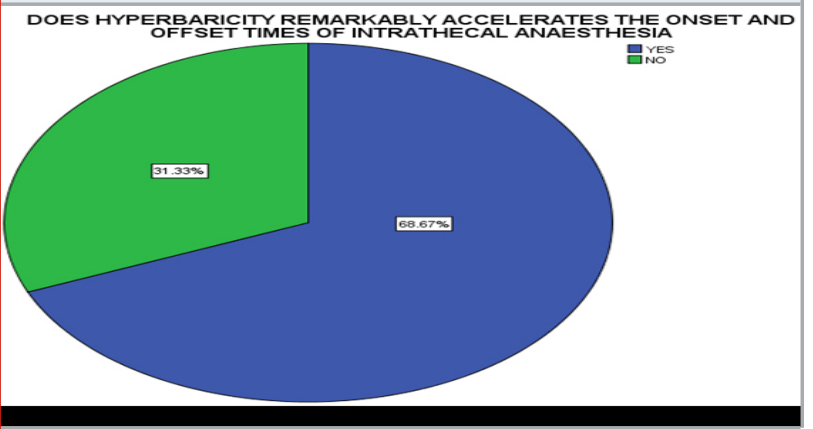

Figure 6: Pie chart showing the percentage of dental students awareness about the faster patient recovery and the type of anesthetic used. 76.67\% (blue) were aware that there was faster recovery after use of hyperbaric prilocaine.

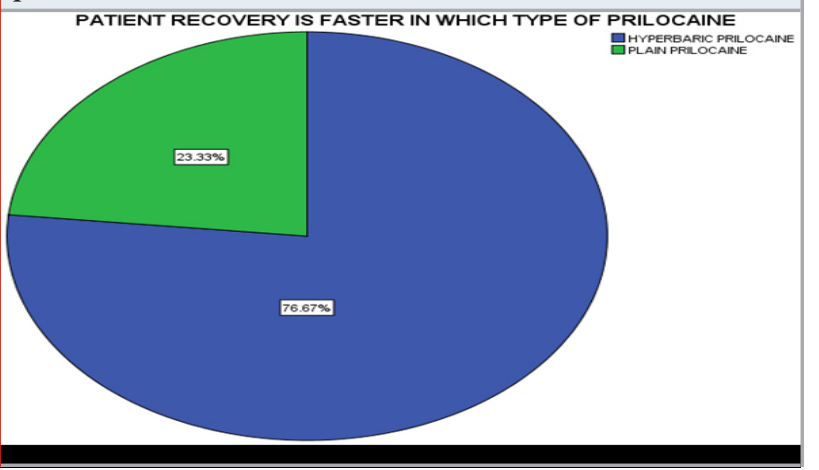

On analysing the response of students on hyperbaricity of prilocaine $68.67 \%$ have reported that they accelerate the onset and offset times of intrathecal anaesthesia while
31.33\% were not aware about it. [FIgure 5] Previous studies have shown that hyperbaric bupivacaine used in the spinal block lasted longer in patients with a restricted block. Hence several local anesthetics have been formulated as hyperbaric solutions for intrathecal administration. (Infante and Van Gessel, 2000).

Figure 7: Pie chart showing the percentage of dental students aware about the lower incidence of urinary retention post surgery after use of different types of anesthetic agents. $40.67 \%$ (blue) were aware that hyperbaric prilocaine had a lower incidence of urinary retention post surgery when compared with other agents. LOWER INCIDENCE OF ACUTE POSTOPERATIVE URINARY RETENTION POST

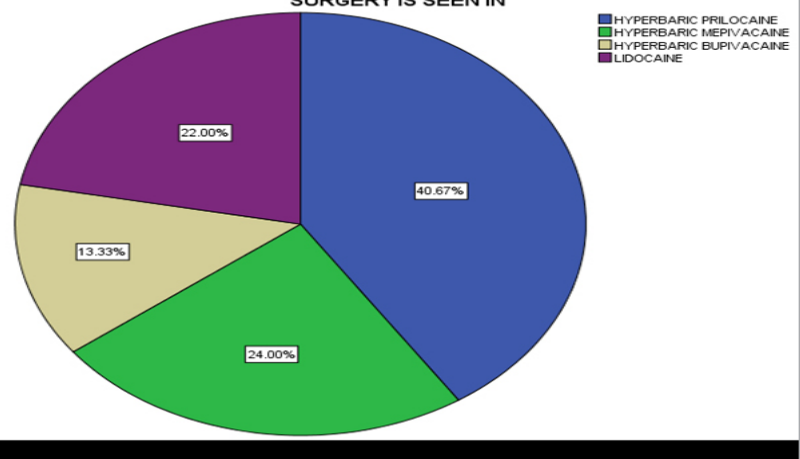

Figure 8: Pie chart showing the percentage of dental students' awareness about the safe and effectiveness of hyperbaric prilocaine. 55.33\% (blue) were aware that hyperbaric prilocaine was safer and effective in use.

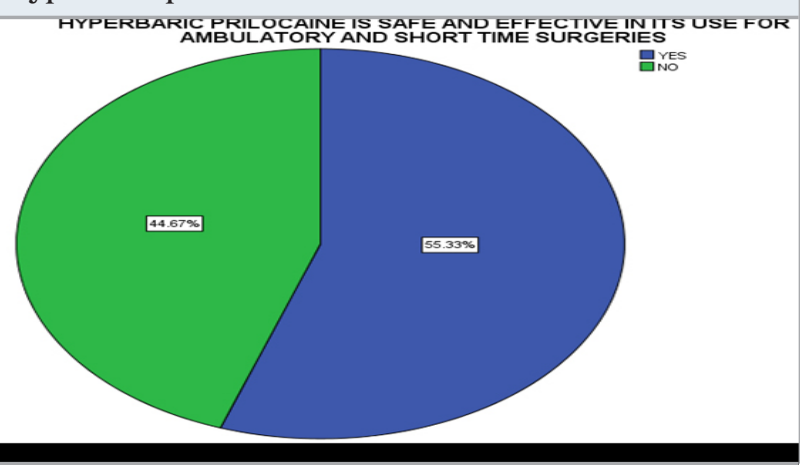

Figure 9: Pie chart showing the percentage of students aware of using hyperbaric prilocaine as an alternative to lidocaine. $63.33 \%$ were unaware about the use of hyperbaric prilocaine as an alternative to lidocaine.

DO YOU THINK $2 \%$ HYPERBARIC PRILOCAINE IS AN AL TERNATIVE DRUG TO

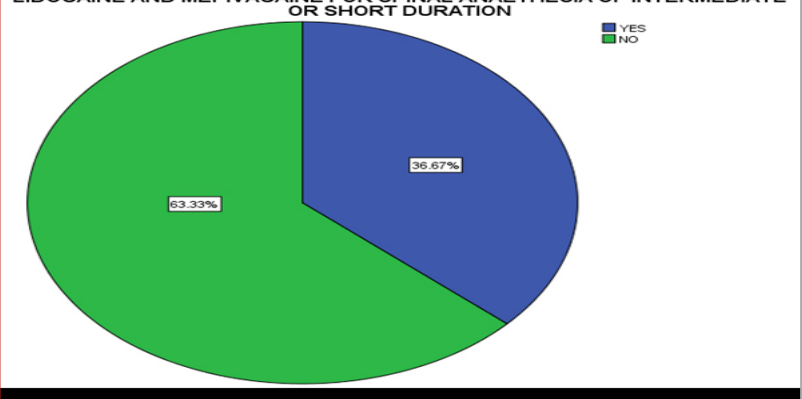


On asking about the patient recovery after using plain and hyperbaric prilocaine, $76.67 \%$ of students have said that hyperbaric prilocaine has faster recovery while 23.33\% have said that plain prilocaine has faster recovery. [FIgure 6] Studies done by Camponovo et al have shown that motor and sensory blocks are established faster; the anesthetic is fixed earlier, and patients recover faster after hyperbaric than after spinal plain prilocaine. (Camponovo et al., 2010).

On assessing the awareness of lower incidence of acute postoperative urinary retention post surgery, $40.67 \%$ have responded as hyperbaric prilocaine, 24\% as hyperbaric mepivacaine, $13.33 \%$ as hyperbaric bupivacaine, 22\% as lidocaine. [FIgure 7] The study confirmed prilocaine as an effective spinal anesthetic for day-case surgery showed no postoperative urinary retention post surgery. (Manassero et al., 2014)

When asked whether hyperbaric prilocaine is safe and effective in its use for ambulatory and shot time surgeries, 55.33\% have answered yes and 44.67\% have answered no. [FIgure 8] When asked about the hyperbaric prilocaine and whether it can be used as an alternative drug to lidocaine and mepivacaine for spinal anaesthesia of intermediate or short duration, $36.67 \%$ have responded yes and 63.33\% have answered no. [FIgure 9] Previous study done by Aguirre et al compared $60 \mathrm{mg}$ of $2 \%$ hyperbaric prilocaine with $12 \mathrm{mg}$ of $0.4 \%$ plain ropivacaine. The offset of the motor block was faster after intrathecal administration of prilocaine. (Aguirre et al., 2015)

Figure 10: Bar graph depicting the association between the awareness of patient recovery after use of different types of prilocaine and age groups. $\mathrm{X}$ axis - age in years; $\mathrm{Y}$ axis- number of students with their responses. 77\% (blue) of students under 21-25 years were aware that there was faster recovery after use of hyperbaric prilocaine. There was a statistically significant association found (Pearson chi square $=24.012 \mathrm{a}, \mathrm{p}$ value $=0.000)(\mathrm{p}<0.05)$. Hence it is statistically significant.

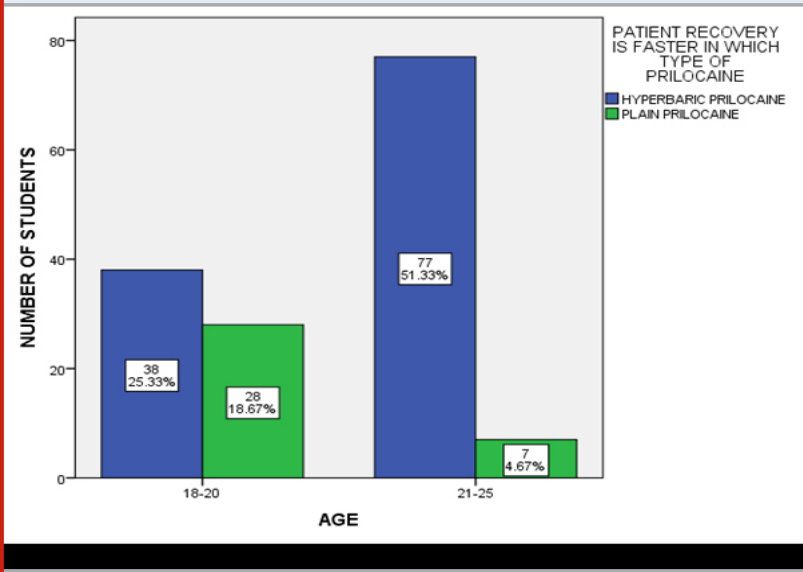

On statistically analysing the association between the awareness of patient recovery and age groups. 38 students (25.33\%) under 18-20 years and 77 students (51.33\%) under 21-25 years have said hyperbaric prilocaine had faster recovery. There was statistically significant association between the awareness of patient recovery and the age groups , $p$ value $=0.000$. [FIgure 10] . Previous study done by Gebhardt et al suggested that hyperbaric prilocaine had faster recovery from spinal anaesthesia when compared with mepivacaine.(Gebhardt et al., 2014)

Figure 11: Bar graph depicting the association between the awareness of effective use of hyperbaric prilocaine and age groups. $\mathrm{X}$ axis - age in years; $\mathrm{Y}$ axis- number of students with their responses. 56\% (blue) of students under 21-25 years were aware of the safety and effective use of hyperbaric prilocaine. There was statistically significant association found (Pearson chi square $=9.921 \mathrm{a}, \mathrm{p}$ value $=0.002)(\mathrm{p}<0.05)$. Hence it is statistically significant.

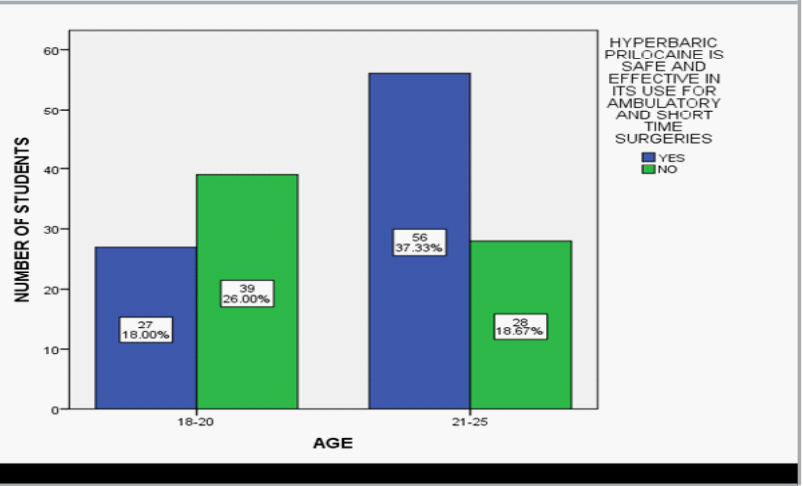

Figure 12: Bar graph depicting the association between the awareness of patient safety after use of hyperbaric prilocaine and age groups. $\mathrm{X}$ axis - age in years; $\mathrm{Y}$ axisnumber of students with their responses. 76\% (blue) of students under 21-25 years were aware that there was patient safety after use of hyperbaric prilocaine. There was a statistically significant association found (Pearson chi square $=30.486 a, p$ value $=0.000)(p<0.05)$. Hence it is statistically significant.

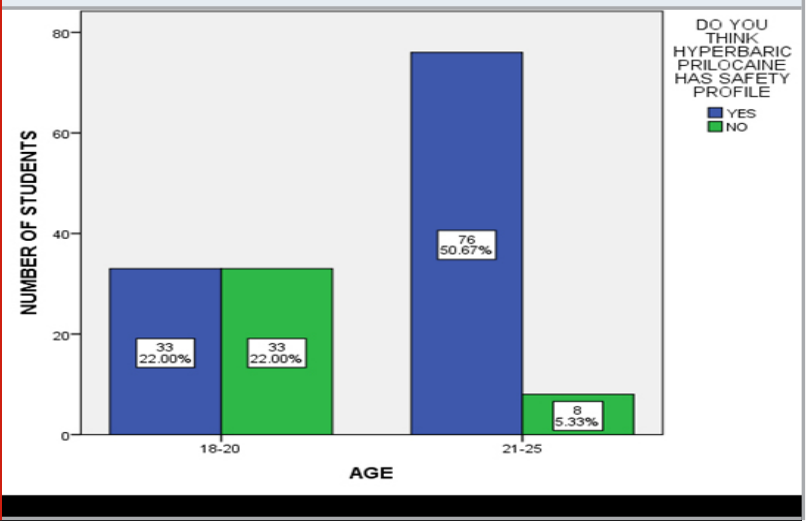

On statistically analysing the association between the awareness of safety and the effective use of hyperbaric prilocaine, 27 students(18\%) under 18-20 years have answered yes and 56 students (37.33\%) under 2125 years have answered yes. There was a significant 
association between awareness of safety and effective use of hyperbaric prilocaine and age groups, $\mathrm{p}$ value $=0.002$. [FIgure 11] Previous studies have shown that hyperbaric prilocaine is safer and effective in use in short time surgeries.(Manassero and Fanelli, 2017)

On statistically analysing the association between the safety profile of hyperbaric prilocaine and age groups, 76 students (50.67\%) under 21-25 years age groups and 33 students (22\%) under 18-20 years have answered yes for hyperbaric prilocaine. There was statistically significant association between awareness on safety profile and age groups, $\mathrm{p}$ value $=0.000$. [FIgure 12]

Figure 13: Bar graph depicting the association between the awareness about hyperbaric prilocaine and gender. $\mathrm{X}$ axis - gender (males/females); $\mathrm{Y}$ axis- number of students with their responses. There was no statistically significant association found (Pearson chi square $=1.698 \mathrm{a}$, $p$ value $=0.192)(p>0.05)$. However, males (blue) had more awareness about hyperbaric prilocaine under both 18-20 years $(49.33 \%)$ and $21-25$ years (38.67\%).

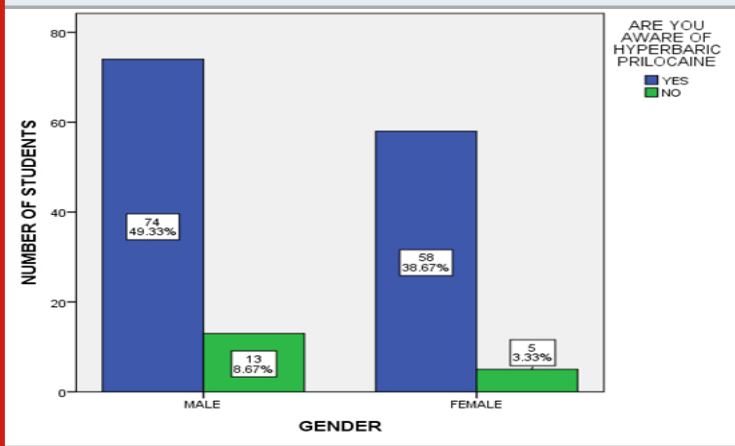

Figure 14: Bar graph depicting the association between the awareness about hyperbaric prilocaine use in short time surgeries and gender. $\mathrm{X}$ axis - gender (males/females); $\mathrm{Y}$ axis- number of students with their responses. Males (blue) had awareness among 18-20 years (37.33\%).There was statistically significant association found (Pearson chi square $=6.484 \mathrm{a}, \mathrm{p}$ value $=0.009)(\mathrm{p}<0.05)$. Hence it is statistically significant.

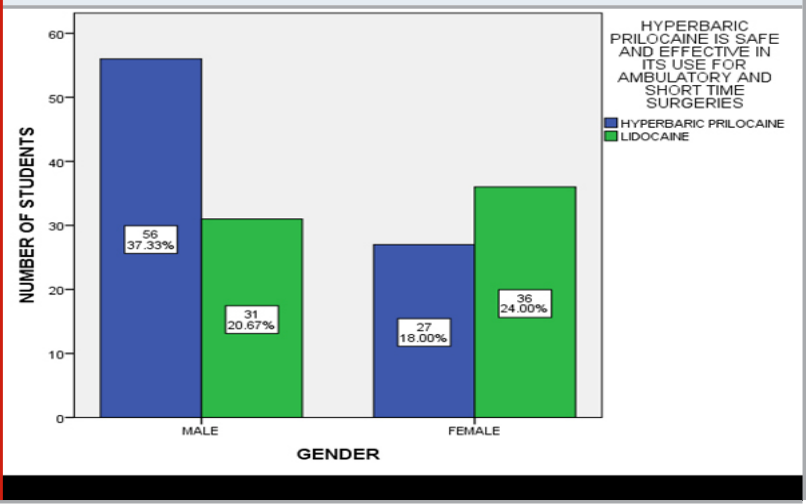

On statistically analysing the association between awareness about hyperbaric prilocaine among gender,74 male students (49.33\%) and 58 females students (38.67\%) have said that they were aware about hyperbaric prilocaine. There was no statistically significant association between the awareness about hyperbaric prilocaine and gender, $\mathrm{p}$ value=0.192. [FIgure 13]

On statistically analysing the association of awareness of safety and effective use of hyperbaric prilocaine among gender, 56 male students (37.33\%) and 27 female students (18\%) have responded that hyperbaric prilocaine is safe and effective. There was a statistically significant association between awareness of safety and effective use of hyperbaric prilocaine among gender, $\mathrm{p}$ value $=0.009$. [FIgure 14] Previous studies have shown that hyperbaric prilocaine is safer and effective in use in short time surgeries.(Manassero and Fanelli, 2017)

On statistically analysing the association of using hyperbaric prilocaine as an alternative to lidocaine among gender, 33 male students ( 22\%) and 22 female students (14.67\%) have responded that hyperbaric prilocaine can be used as an alternative. There was no statistically significant association between the awareness of using hyperbaric prilocaine as an alternative among gender, $p$ value $=0.710$. [FIgure 15] Previous studies have shown prilocaine as a same duration of action than an equal dose of lidocaine resulting an alternative drug for spinal anesthesia of intermediate or short duration.(Østgaard, Hallaråker and Ulveseth, 2000; Weert et al., 2000)

Figure 15: Bar graph depicting the association between the awareness about hyperbaric prilocaine as an alternative to lidocaine and gender. $\mathrm{X}$ axis - gender (males/females); $\mathrm{Y}$ axis- number of students with their responses. There was no statistically significant association found (Pearson chi square $=3.865 \mathrm{a}, \mathrm{p}$ value $=0.710)(\mathrm{p}>0.05)$. However, Males (blue) had awareness about hyperbaric prilocaine under both 18-20 years (22\%) and 21-25 years (14.67\%).

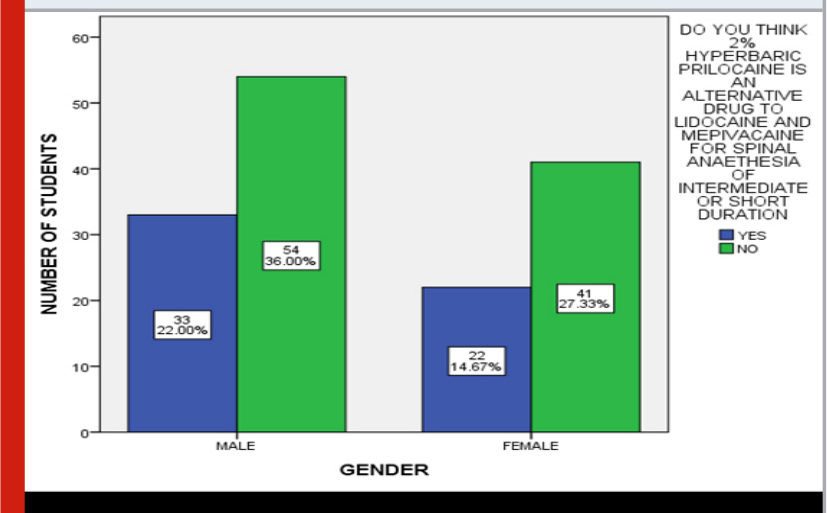

The limitation of the present study was that it was an online survey and the response from students may not feel encouraged to provide accurate, honest answers. There are chances for the students of not feeling comfortable providing answers that present themselves unknown. The sample size of the study was smaller which could define the generalised population. And so multicentric surveys can be conducted on a larger population. 


\section{CONCLUSION}

Within the limitations of the present study, the awareness about the uses and properties of hyperbaric prilocaine was moderate. There was higher awareness among 21-25 years age group students which showed a statistically significant association. Though there was higher awareness among male students yet no significant association was found among gender. Research on the use of hyperbaric prilocaine in dentistry can be done in future.

Authors Contribution: Prashaanthi.N contributed acquisition of data, analysis, literature collection and also in drafting the article and revising it critically for important intellectual content.

Dhanraj Ganapathy contributed in conception, the study design, interpretation of data, formatting, manuscript preparation, supervision and guidance.

\section{ACKNOWLEDGEMENTS}

We take pleasure to acknowledge our University for granting permission to utilize the patient records for data collection

Conflict Of Interest: The authors declare that there is no conflict of interest

\section{REFERENCES}

Aguirre, J. et al. (2015) 'Intrathecal hyperbaric 2\% prilocaine versus $0.4 \%$ plain ropivacaine for same-day arthroscopic knee surgery: a prospective randomized double-blind controlled study', Canadian Journal of Anesthesia/Journal canadien d'anesthésie. Springer, 62(10), pp. 1055-1062.

Ambrosoli, A. L. et al. (2016) 'A randomised controlled trial of intrathecal blockade versus peripheral nerve blockade for day-case knee arthroscopy', Anaesthesia, 71(3), pp. 280-284.

Anbu, R. T. et al. (2019) 'Comparison of the Efficacy of Three Different Bone Regeneration Materials: An Animal Study', European journal of dentistry, 13(1), pp. 22-28.

Ariga, P. et al. (2018) 'Determination of Correlation of Width of Maxillary Anterior Teeth using Extraoral and Intraoral Factors in Indian Population: A Systematic Review', World Journal of Dentistry, 9(1), pp. 68-75. Ashok, V. and Ganapathy, D. (2019) 'A geometrical method to classify face forms', Journal of oral biology and craniofacial research, 9(3), pp. 232-235.

Camponovo, C. et al. (2010) 'A prospective, doubleblinded, randomized, clinical trial comparing the efficacy of $40 \mathrm{mg}$ and $60 \mathrm{mg}$ hyperbaric $2 \%$ prilocaine versus $60 \mathrm{mg}$ plain $2 \%$ prilocaine for ...', Anesthesia \& pain control in dentistry. journals.lww.com. Available at: https://journals.lww.com/anesthesia-analgesia/ FullText/2010/08000/A_Prospective,_Double_Blinded,
Randomized,.49.aspx.

Duraisamy, R. et al. (2019) 'Compatibility of Nonoriginal Abutments With Implants: Evaluation of Microgap at the Implant-Abutment Interface, With Original and Nonoriginal Abutments', Implant dentistry, 28(3), pp. 289-295.

Evaluation of Corrosive Behavior of Four Nickelchromium Alloys in Artificial Saliva by Cyclic Polarization Test:An in vitro Study' (2017) World Journal of Dentistry, 8(6), pp. 477-482.

Ganapathy, D. M., Kannan, A. and Venugopalan, S. (2017) 'Effect of Coated Surfaces influencing Screw Loosening in Implants: A Systematic Review and Meta-analysis', World Journal of Dentistry, 8(6), pp. 496-502.

Gebhardt, V. et al. (2014) 'Spinal hyperbaric prilocaine vs. mepivacaine in perianal outpatient surgery', Central European journal of medicine, 9(6), pp. 754-761.

Gupta, P., Ariga, P. and Deogade, S. C. (2018) 'Effect of Monopoly-coating Agent on the Surface Roughness of a Tissue Conditioner Subjected to Cleansing and Disinfection: A Contact Profilometric Study', Contemporary clinical dentistry, 9(Suppl 1), pp. S122S126.

Infante, N. E. K. and Van Gessel, E. (2000) 'Extent of hyperbaric spinal anesthesia influences the duration of spinal block', : The Journal of .... anesthesiology.pubs. asahq.org. Available at: https://anesthesiology.pubs. asahq.org/article.aspx?articleid=1945662.

Jain, A. R. (2017a) 'Clinical and Functional Outcomes of Implant Prostheses in Fibula Free Flaps', World Journal of Dentistry, 8(3), pp. 171-176.

Jain, A. R. (2017b) 'Prevalence of Partial Edentulousness and Treatment needs in Rural Population of South India', World Journal of Dentistry, 8(3), pp. 213-217.

Kaban, 0. G. et al. (2014) 'Spinal anaesthesia with hyperbaric prilocaine in day-case perianal surgery: randomised controlled trial', TheScientificWorldJournal, 2014, p. 608372.

Kreutziger, J. et al. (2010) 'Urinary retention after spinal anaesthesia with hyperbaric prilocaine $2 \%$ in an ambulatory setting', British journal of anaesthesia, 104(5), pp. 582-586.

Lacroix, S. P. et al. (2019) 'Predictability of the duration of motor blockade induced by unique injection of intrathecal prilocaine - an observational study', Journal of physiology and pharmacology: an official journal of the Polish Physiological Society, 70(3). doi: 10.26402/ jpp.2019.3.08.

Manassero, A. et al. (2014) 'Comparison of unilateral and bilateral spinal anesthesia with 2\% hyperbaric prilocaine in day-case inguinal herniorrhaphy: a randomized controlled trial', Minerva anestesiologica, 80(6), pp. 685-691.

Manassero, A. and Fanelli, A. (2017) 'Prilocaine hydrochloride $2 \%$ hyperbaric solution for intrathecal injection: a clinical review', Local and regional 
anesthesia, 10, pp. 15-24.

Østgaard, G., Hallaråker, O. and Ulveseth, O. K. (2000) 'A randomised study of lidocaine and prilocaine for spinal anaesthesia', Acta. Wiley Online Library. Available at: https://bit.ly/3arNy5Z.

Palumbo, P. et al. (2019) 'Tailored Surgery in Inguinal Hernia Repair. The Role of Subarachnoid Anesthesia: A Retrospective Study', Open medicine: a peer-reviewed, independent, open-access journal, 14, pp. 639-646.

Ranganathan, H., Ganapathy, D. M. and Jain, A. R. (2017) 'Cervical and Incisal Marginal Discrepancy in Ceramic Laminate Veneering Materials: A SEM Analysis', Contemporary clinical dentistry, 8(2), pp.
272-278.

St George, G. et al. (2018) 'Injectable local anaesthetic agents for dental anaesthesia', Cochrane database of systematic reviews, 7, p. CD006487.

Varghese, S. S., Ramesh, A. and Veeraiyan, D. N. (2019) 'Blended Module-Based Teaching in Biostatistics and Research Methodology: A Retrospective Study with Postgraduate Dental Students', Journal of dental education, 83(4), pp. 445-450.

Weert, K. de et al. (2000) 'The incidence of transient neurological symptoms after spinal anaesthesia with lidocaine compared to prilocaine', Anaesthesia, pp. 1020-1024. doi: 10.1046/j.1365-2044.2000.01618-4.x. 